\title{
TEACHING LISTENING AMONG BANGLADESHI LEARNERS: A CASE STUDY ON TEACHERS' EFFECTIVE FEEDBACK AND STUDENTS' SITUATIONAL IMPRESSIONS
}

\author{
Md. Kawser Ahmed \\ Senior Lecturer \\ Department of English and Modern Languages \\ IUBAT-International University of Business Agriculture and Technology \\ Uttara, Dhaka, Bangladesh \\ E-mail: kawser.ahmed@iubat.edu
}

Received: October 08, 2021 Accepted: October 29, 2021 Online Published: November 10, 2021

DOI: 10.46281/aijssr.v9i1.1432

URL: https://doi.org/10.46281/aijssr.v9i1.1432

\begin{abstract}
Listening centralizes upon the comprehension of messages coupled with pronunciations or sounds from speakers-be they are native or non-native and local or foreigner in the scopes of formal conversation, business talk and classroom lectures in the context of Bangladesh. Bangladeshi learners find listening as a complex and incomprehensible skill of four skills of English language. They often are not able to understand pronunciation patterns and accentual variations used in speeches or conversations. Listening requires systematic strategies in understanding audio or vocal track for which logistic support is highly essential. Managing technical support is at times difficult for teachers and administration because of financial constraints. This study will concentrate on how teachers ensure pedagogical supports and experimental aspects to help learners understand listening effectively with methodological study. This paper will deal with how learners overcome the stages of listening difficulties and comprehend different phonological aspects successfully. In addition, one of the prime concentrations of this paper is to identify impediments of teaching listening, teachers' inefficiency in listening skill and students' negligence in achieving mastery on listening.
\end{abstract}

Keywords: Administration, Audio, Comprehension, Logistic, Pedagogical, Pronunciation, Vocal.

\section{INTRODUCTION}

It is universally acknowledged that listening is an indirect, passive and silent language skill because it focuses on the reception of inputs, words and verbal expressions from surrounding. Not only the physical setting is essential, but also psychological aspects are essential. Lists a series of micro-skills of listening which are 'predicting what people are going to talk about', 'guessing at unknown words or phrases without panicking' and 'using one's own knowledge of the subject to help one understand'. She additionally identified that listening includes accepting relevant 
information and rejecting unnecessary information, recognizing discourse markers like 'well', 'now' and 'finally' and understanding cohesive devices.

Teaching listening unlike other language skills involves a number of techniques, teachers from non-native countries like Bangladesh face remarkable problems, which teachers should maintain in the arena of listening skill. Listening is overtly related to speaking as for the speakers speak and the listeners listen- sound, sound patterns, words distinction and conversation. Teachers irrespective of native or non-native cannot make listening well-understandable to students who remain immensely immersed in unbound the meaning of listening.

Listening refers to paying attention to and perceiving what you hear and is an essential skill for effective communication. Pitiably teachers and students often overlook the importance of listening because they remain immensely engrossed on the course how to speak the language.

Teachers adopt different techniques and strategies to teach students how to acquire mastery over listening as further claimed, "Listening is in some ways more difficult than speaking" which makes us understand the importance and difficulty of learning listening. Listening strategies focus on activities or techniques which in fact directly contribute to the understanding of listening input.

Chen (2011) stated that interaction does not only happen among native speakers (NSs) and non-native speakers (NNSs) but also among NNSs themselves. Hereby it is a matter of investigation on how well NNS listeners successfully understand the accents or accentual patterns produced by other NNSs.

Approaches to listening are classified into 'Bottom-up processes and 'Top-down processes. Bottom-up process refers to "perceiving and parsing the speech stream at increasingly larger levels beginning with auditory-phonetic, phonemic, syllabic, lexical, syntactic, semantic, propositional, pragmatic and interpretive". It entails the study listening bits by bits from lower level to upper level. On the other some researcher defined that top-down process is considered as to the opposition of bottom-up process. Nunan (2003) dealt with the top-down process that learners start listening from background knowledge-it might happen from content schema, which focuses on general information based on previous learning and life experience, or textual schema, which focuses on the awareness of the kinds of information used in a given situation. In fact listening exhibits a number of works which make the learners go through challenging situations. Listening includes the interpersonal and interpretive patterns of communication. It compels the listener to play the role of active participant in listening like face-to-face conversation and passive role in listening to other when people speak or present.

In this paper, scenario of teaching listening skill, feedbacks from teachers and perceptions from students will be discussed in the context of Bangladesh along with studies conducted among teachers as teaching listening and students as understanding listening.

\section{TEACHING LISTENING: A FRAMEWORK IN THE CONTEXT OF BANGLADESH}

To ELT teachers and learners irrespective of any class or stage of language study, teaching and learning listening is largely ignored in Bangladesh. What reported that learners focus more on how to speak well than how to listen well is pathetically relevant in the practical scenario of suggesting how to be a good listener? Listening skill is not a dormant and passive language skill, what teachers and students frequently misuse it, and they think they will concentrate on listening once they are competent enough in other language skills. Nunan (2003) however contrasted that listening is 'an active and purposeful process' in which we hear what speakers produce before us. 
Some researcher investigated that students have got poor listening skill from their primary and intermediate level to tertiary level. Even they do not think listening skill as the most emphasized at any of these levels.

Some researcher identified that most of the Bangladeshi learners do not have adequate vocabulary which can be held as the shortcoming in listening. He further told that learning vocabulary is the most important aspect in listening in which they will familiarize and understand the new manner of pronunciations.

Alam and Sinha (2009) presented that Bangladeshi students are not taught listening skills at their secondary and higher secondary level of education. In such a case teaching them using native context at the beginning of tertiary education creates problems.

Alam and Sinha (2009) presented the fact that teaching at the tertiary education of Bangladesh is done by lectures and classes are conducted in English medium. In addition, teachers have higher degree English speaking countries with different accents and they deliver lectures with foreign which pose a problem for the Bengali medium students. Jahan and Jahan (2008) reported that in higher education only 14\% students come from English medium education.

Students who face problems in real life classrooms might also have problem in understanding foreign programs and thus to understand languages ostensibly they should spend more time in receiving messages from radio, television announcements and other relevant situations (Littlewood, 1981).

The perspective of teaching listening in real life situations like classroom, teaching and learning related activities and academic activities in the educational system of Bangladesh is entirely absent. The effective cultivation of listening skills is obvious in the English medium education of Bangladesh as it goes through British or American education system.

\section{REVIEW OF LITERATURE}

Rost (2002) and Vandergrift (2004) mentioned that listening skill was not seriously seen as worthy of research or pedagogical concentration because listening was considered as passive skill. Despite having all of the orthodox impressions to listening, listening plays a significant role in both language learning, communication, academic pursuit and current English curriculum.

Maniruzzaman (2002) identified that listening appears as a challenging skill for the foreign language learners like Bangladeshi learners because learners need substantial endeavors to achieve this skill. He also opined that Bangladeshi learners face this problem because they do not have a good scope to have mastery upon listening skill.

Sadighi \& Zare (2006) told that a number of researchers claim that listeners who are effective in listening are more efficient to engage in top-down processing to assist their comprehension of the aural input. On the other hand, ineffective listeners depend much on bottomup processing and for this reason they are deficient in top-down processing skills.

It can be said further that listeners who are less-skilled performed much better on "local questions", that required the listeners to locate details and facts, than "global questions", which required the listener to synthesize information, draw conclusions, make inferences and so on.

Chen (2013) told that listening comprehension is a complex ongoing process which includes the interaction of various factors and many learners have difficulty to understand spoken input and they are not fully aware of why such variation happens in listening.

Some researcher investigated that EFL learners expose problems in listening to academic lectures completely. Students highlighted some of the problems which included the fast speed of 
delivery of lectures, new terminology and concepts, difficulties in concentrating as it was done in foreign language, and problems related to the physical environment.

Goh (2000) identified that learners have problems in real time listening. This concept is exemplified by Anderson who initiated three models of language comprehension such as perception, parsing and utilization. These kinds of problems were related to the process of perception which is known as low-level for the identification of word and failure in attention. Likewise, some other problems were embedded with inefficient parsing and failure in utilization which is known as high-level process. Goh (2000) came to the conclusion that listeners having less-proficiency have more problems with low-level processing.

From a recent study by Graham (2006) cited in Chen (2013) that the main listening problems were related to the speedy delivery of text leading to failure in identifying and recognizing words in a stream of input. It can be understood from these studies, although having identified a range of listening problems related to factors of text, task, speaker and listener, that learners identified most common problems which are fast speech rate and unfamiliar words.

Chen (2013) further discussed that this may suggest that most learners have limited knowledge of their ways of dealing with listening input and little awareness of the actual problems when they go for their online processing. In this circumstance, comprehension usually breaks down at the low-level of processing and thus inhibits listeners from arriving at successful comprehension.

Some researcher reported that the listening problems have been ignored and unsolved for a long time as it is in the conventional method of teaching and involve learners in practicing answering the questions of listening test and giving explanation of meaning.

Underwood (1989) identified some barriers which exhibit obstacles to effective comprehension in the process of listening. Firstly, listeners face some problems to go with the speed of speech and they cannot at the same rate the speakers speak. Secondly, listeners often get failed to understand the words used repeatedly which poses a big difficulty to understand literature. Similarly students are limited to play the recording once again. Thirdly, listeners might not have a sound knowledge in the context which deters them to have mutual knowledge to understand effective communication.

What Underwood (1989) identified as a bunch of obstacles in the process of listening is largely applicable in the context of Bangladeshi learners who almost face same sort of problems. Some researcher opined that students have problems in the way of comprehending listening which is related to listening materials. In fact researchers redefined that listening does not have great importance and for this purpose teachers are not interested let them understand different strategies in listening.

Bloomfield et al. (2010) told that pronunciation is the greatest hurdle in listening comprehension one of the serious problems of listening comprehension is related to the pronunciation of words that is different from the way they appear in print. Due to the fact that the spoken language varies to the form of the written language, the recognition of words that make the oral speech can create some difficulties for students.

Hasan (2000) indicated that unfamiliar words, difficult grammatical structures, and the length of the spoken passages are the most important factors that cause problems for learners' listening comprehension. Yagang (1994) identified four problems in comprehending listening which are the message, the speaker, the listener, and the physical environment. Some researcher pointed out that listener, speaker, medium, and environment issues are the main catalysts that affect listening comprehension. 


\section{RESEARCH METHODS AND INSTRUMENTS}

In this section of the paper, I will discuss research methods and instruments like participants, data collection, data analysis and findings.

\section{Participants}

A survey work was conducted among the students of first semester of a private university in Bangladesh who were required to complete some basic courses on English language like listening and speaking. The number of participants was 60 attending from different departments like engineering, business and humanities. They were given a questionnaire equipped with 5 more questions and were given instructions adequately in order for them to understand and give their opinions appropriately. Since they came across twelve years of study from their previous academic life, they listened to conversation from teachers especially at school and college in language classes, commentary of various forms of games and sports and speeches from native countries such as Prime Ministers and Presidents of the world. Based upon their previous experience, I expected that they would understand the determiners set on the questionnaire and mark them accordingly. They were also assured that they would neither be judged nor assessed their performances in order to reduce their anxiety and ensure spontaneity. Being announced everything in detail, survey work started and it took nearly 30 minutes to complete the whole process. Afterwards all of the questionnaires were taken from the participants with expressing gratitude for slotting their valuable time for participating survey work.

\section{Data Collection}

After I had got all the filled in questionnaires I went for methodical measurement through MS Excel software to ensure more validity of the study and its results. Previously remarked, I had set five different determiners in the questionnaire and I made a quantitative measurement mentioning number of participants, average, standard deviation and mean in order to validate the data processing tasks.

The areas of questions were:

- Whether listeners understood native like pronunciation when they listened to class lecture or in discussion.

- Whether listeners kept all of the information in memory while they listened to speed talking in real life listening.

- Whether listeners understood the use of linkers, fillers and pause markers while listening

- Whether listeners understood clearly all of the contextual information, explanation and discussion in memory when they listened from teachers or demonstrators

- Whether listeners could comprehend the news or bulletins telecast in international television channel.

The participants marked all of the determiners in an appropriate manner and then they wrote their written impressions inside the comment box indicated at the bottom of the questionnaire. In the next section of the paper will be the discussion of results along with some demo of written experiences what participants came by from different speakers. 
Table 1. Numerical Data on Survey Work

\section{FINDINGS AND DISCUSSION}

\begin{tabular}{|c|c|c|c|c|c|c|}
\hline $\begin{array}{l}\text { Questions/D } \\
\text { eterminers }\end{array}$ & Understandable & $\begin{array}{l}\text { Partially } \\
\text { understandable }\end{array}$ & \begin{tabular}{|l|} 
Not \\
understandable
\end{tabular} & \begin{tabular}{|l|} 
Percentage of \\
Understandable
\end{tabular} & $\begin{array}{l}\text { Percentage of } \\
\text { Partially } \\
\text { understandable }\end{array}$ & $\begin{array}{l}\text { Percentage } \\
\text { Not } \\
\text { understandable } \\
\end{array}$ \\
\hline $\begin{array}{l}\text { Understandin } \\
\text { g native like } \\
\text { pronunciation } \\
\text { in class }\end{array}$ & 15 & 38 & 7 & 13 & 34 & 6 \\
\hline \begin{tabular}{lr}
\multicolumn{2}{l}{ Understandin } \\
$\mathrm{g}$ & words \\
during & the \\
speed & of \\
talking & \\
\end{tabular} & 18 & 36 & 6 & 16 & 32 & 5 \\
\hline $\begin{array}{l}\text { Understandin } \\
\mathrm{g} \quad \text { fillers, } \\
\text { pause } \\
\text { markers and } \\
\text { linkers }\end{array}$ & 14 & 42 & 4 & 12 & 38 & 3 \\
\hline $\begin{array}{l}\text { Understandin } \\
\mathrm{g} \text { teachers' } \\
\text { contextual } \\
\text { discussion }\end{array}$ & 16 & 39 & 5 & 14 & 35 & 4 \\
\hline $\begin{array}{l}\text { Understandin } \\
\text { g TV news or } \\
\text { bulletin }\end{array}$ & 17 & 38 & 5 & 15 & 34 & 4 \\
\hline Mean & 16 & 38.6 & 5.4 & & & \\
\hline $\begin{array}{l}\text { Standard } \\
\text { Deviation }\end{array}$ & 1.58 & 2.19 & 1.14 & & & \\
\hline
\end{tabular}

Table 1 deals with the detailed findings from the study conducted among participants on 5 different Questions/Determiners, and other column determiners titled as Understandable, Partially understandable and Not understandable. On the other hand, it displays Percentage of Understandable, Percentage of Partially understandable and Percentage of Not understandable. It was discussed earlier that the number of participants was 60 who attended the survey work right after the completion listening test, though their papers were not marked and it was aimed to get their impressions only.

Firstly, on the determiner of Understanding native like pronunciation in class 15 people marked it Understandable, 38 people Partially understandable and 7 people Not understandable. In this case, the percentage of each determiner like 13\% for Understandable, 34\% for Partially understandable, and $6 \%$ for Not understandable.

Secondly, on the determiner of Understanding words during the speed of talking 18 people marked it Understandable, 36 people Partially understandable and 6 people Not understandable. In this case, the percentage of each determiner like 16\% for Understandable, 32\% for Partially understandable, and 5\% for Not understandable.

Thirdly, on the determiner of Understanding words during the speed of talking 14 people marked it Understandable, 42 people Partially understandable and 4 people Not understandable. 
In this case, the percentage of each determiner like $12 \%$ for Understandable, $38 \%$ for Partially understandable, and 3\% for Not understandable.

Fourthly, on the determiner of Understanding teachers' contextual discussion 16 people marked it Understandable, 39 people Partially understandable and 5 people Not understandable. In this case, the percentage of each determiner like $14 \%$ for Understandable, $35 \%$ for Partially understandable, and $4 \%$ for Not understandable.

Fifthly, on the determiner of Understanding TV news or bulletin 17 people marked it Understandable, 38 people Partially understandable and 5 people Not understandable. In this case, the percentage of each determiner like $15 \%$ for Understandable, $34 \%$ for Partially understandable, and $4 \%$ for Not understandable.

However, from this study it is obvious the attainment of Mean and Standard Deviation where Mean is 16 on Understandable, 38.6 on Partially understandable and 5.4 Not understandable and Standard Deviation is 1.58 on Understandable, 2.19 on Partially understandable and 1.14 on Not understandable.

\section{Comments from Participants}

Likewise, it is relevant to quote out the comments what participants made at the time of survey work and such statements made researchers understand about the impressions of learners to the listening skill.

"In the long conversation or discussion, I mess up with ideas, topics or contexts which make me lose my attention and research what the speakers have talked on. So I have a good problem in understanding discussion properly." (One of the participants commented such.)

"I experience the problem of accentual pattern and cannot catch pronunciation effectively. Though all of the words seem to be familiar to me, I cannot understand at the time of talk, discussion and presentation." (Another participant made such kind of comment.)

"Frankly speaking, since I am a non-native listener and learner, I do not understand most the words or phrases produced by speakers. The obvious reason is that I do not have sufficient words in my vocabulary possession. For this reason, I cannot get my speakers conveniently at the time of conversation, news reading and reality of TV show." (One of the participants made such comment.)

\section{RECOMMENDATIONS}

Bangladeshi teachers and learners are by no means reluctant to understand the scope and horizon of listening skill which culminate an inappropriate and vague understanding of message, topic and context. Education academically and formally commencing from primary education to higher education, listening as an effective channel of communication is overlooked or very often ignored. Relevantly, Nunan (1998) pointed out that skills like listening and reading are considered as 'secondary skills' which means to other ends, rather than ends in themselves.

In this section, some recommendations perceiving the barriers or limitations of listening skill of Bangladeshi learners are outlined.

\section{Learners' Active Participation}

Listening is, in most of the course curriculum and syllabus design, not equal value in proportionate to the value ascribed upon other skills like speaking. Listening is a one kind of skills. We can provide students in performing that kind of skill which will help them to be better listeners (Harmar, 1998). In fact listening is a direct language skill without which speaking loses its effectiveness in the way of communication. For this much of the research has been conducted on 
listening and term “Comprehensible Input: came into its existence by Krashen (1982), O'Malley (1985), Dunkel (1991) and Feyten (1991). Teachers of Bangladesh need to make the classroom learner-centered and make students much oriented to real life listening activities or drills. Some researcher opined that the pre-eminence of listening comprehension especially in the early stages of language learning ensures four main advantages like cognitive, efficiency, utility and affective advantages. Learners' intelligence and power of perception will not be developed if they remain beyond the active participation in listening performance and real life experience.

\section{Effective ELT Policy}

In the education policy of Bangladesh, some drawbacks are ostensible which deter the overall progress of teaching and learning English effectively. Ara (2009) criticized that many policies were taken and subsequently changed in the aspect of teaching and learning of English since the independence of Bangladesh (Ara, 2009). Grammar-Translation Method (GTM) had been practiced in the EFL context of Bangladesh since the regime of British Empire. Practically this GTM proved its effectiveness to make students enable to communicate in oral and written English (Hamid \& Baldauf, 2008). The state must think over the efficacy of forming effective ELT policy in order that language practitioners, teachers and students can understand the ELT policy to meet the challenges of new civilization. Textbooks which are approved by English Language Teaching Improvement Project (ELTIP) are supposed to follow techniques and activities of Communicative Language Teaching (CLT). Thus learners will be able to learn English language in an interactive way in association with four skills - listening, speaking, reading and writing (Hamid \& Baldauf, 2008). As a whole, constant ELT policy and planning will ensure the maximum effectiveness of four language skills especially listening which remains neglected in the context of Bangladesh.

\section{Initiation of Effective Approaches}

Teachers and language trainers should adopt various approaches in order to ensure pragmatic listening practice inside classroom. Approaches or techniques are the tools or measures which affect the rate of progress in aural-oral skill. Li and Renandya (2012) suggested that specifically, vocabulary instruction for vocabulary learning, preparation topically, mechanically slowdown of the rate of sound and repeated listening are thought to be effective approaches to facilitating learner comprehension of the L2 spoken text. Vandergrift (2004) opined, "an awareness of both top-down and bottom-up processes and their relative contribution to comprehension in different contexts and at different levels of language proficiency is fundamental to a theoretically grounded pedagogy of L2 listening comprehension". Johnson (1994) outlined some of the strategies like pairing students with supportive partners, instructing students to make questions and answers, using tape-recording with microphone use while test is going one and inviting students for role-play, puppets activities and getting involved in participatory talk. Indeed teachers and classroom instructors should provide learners with sufficient guidelines, approaches and techniques to make them comfortable in listening work.

\section{Adequate Training for Teachers and Trainers}

Teachers and language trainers should keep in mind that students are the perfect imitators of what their teachers and trainers do in the way of pronouncing words, using fillers and stress markers, intonation marks and phonological aspects. In the process of ensuring effective listening, teachers and trainers should have adequate trainings on many different linguistic aspects. Local proficient teachers, speech therapists and foreign language experts should be invited to train local teachers 
and thus they would be more proficient to teach students effective listening skill. Teachers should be given training how to conduct listening classes crowded with huge number of students in the poor socio-economic set up of Bangladesh as it requires the assembly huge number of logistic supports like headphone, microphone, loud speaker, computer and constant supply of electricity.

\section{CONCLUSION}

The study conducted among the tertiary students of Bangladesh exposed that they failed to understand conversation, discussion and lectures delivered in target language for they had been accustomed to listening in their own native language. Participants expressed their impressions that they could not retain their attention while they were listening audio track played before the survey work and they were overlapping of one topical discussion with another one. The study also revealed that participants could not find the connection of linkers or pause markers and thematic or subjective discussion in the classroom. This problem became worsening when they attended the science and engineering courses and understanding methodical presentation on scientific and engineering made them confused during teachers' presentation. Overall participants gave their impressions that they could understood discussion and mode of presentation partially not confidently. Similarly the level of students' understanding can be held as the potential barrier in the smooth way of conducting listening oriented class. Ur (1995) the level of students play a good role in listening long passages and keeping all the listened stories in mind. In fact it is not easy for the lower level students to listen to more than three minutes and complete the activities. It is recommended that texts with short listening facilitate listening comprehension and reduce monotony and keep learners concentrating. In this case, as Bangladeshi learners have much problem in understanding and grasping information while listening, teachers should segment the whole class into small ones for micro-listening with small duration audio clip. By engaging them into real life listening, teachers can identify some problems from individual listeners and then he should spend more time with them and help them to practice more sessions or audio clips confidently.

\section{REFERENCES}

Alam, Z. \& Sinha, B. S. (2009). Developing Listening Skills for Tertiary Level Learners. The Dhaka University Journal of Linguistics, 2(3), 19-52.

Akter, Z. (2006). Redefining 'Communicative Competence' in Teaching English as a Foreign Language in Bangladesh. Harvest: Jahangirnagar Studies in Language and Literature, 21, 13-22.

Ara, S. (2009). The contribution of the communicative language teaching approach to teaching writing in the English classroom. Harvest: Jahangirnagar Studies in Language and Literature, 24, 9-26.

Bloomfield, A., Wayland, S. C., Rhoades, E., Blodgett, A., Linck, J., \& Ross, S. (2010). What makes listening difficult? Factors affecting second language listening comprehension. MARYLAND UNIV COLLEGE PARK. Retrieved from http://www.google.es/url?sa=t\&rct=j\&q=\&esrc=s\&frm=1\&source=web\&cd=3\&ved=0C EgQFjAC\&url=htt p://wwwdliflc.edu/file.ashx?path\%3Darchive/documents/CASL_study_FINAL_Lit_Rev. 
pdf\&ei=kFfMUu vJ8PE0QXVm4HoDg\&usg=AFQjCNGUJK1MDBEcB8vygOP4Hd2mh1uIQg

Chen, H. C. (2011). Second language timing patterns and their effects on native listeners' perceptions. Concentric: Studies in Linguistics, 36(2), 183-212.

Dunkel, P. A. (1991). Listening in the native and second/foreign language: Toward an integration of research and practice. TESOL Quarterly, 25(3), 431-457.

Feyten, C. M. (1991). The power of listening ability: An overlooked dimension in language acquisition. Modern Language Journal, 75(2), 173-180

Goh, C. (2000). A cognitive perspective on language learners' listening comprehension problems. System, 28, 55-75.

Graham, S. (2006). Listening Comprehension: The Learners' Perspective. System, 34, 165-182. http://dx.doi.org/10.1016/j.system.2005.11.001

Hamid, M. O., \& Baldauf, R. B. (2008). Will CLT bail out the bogged down ELT in Bangladesh?. English Today, 24(3), 16-24.

Harmar, J. (1998). How to Teach English. London: Longman

Hasan, A. (2000). Learners' Perceptions of Listening Comprehension Problems. Language, Culture and Curriculum, 13, 137-153. http://dx.doi.org/10.1080/07908310008666595

Jahan, A., \& Jahan, N. (2008). Teaching Presentation Skills to Tertiary Students in Bangladesh. Stamford Journal of English, 4, 38-57.

Johnson, J. (1994). The National Oracy Project. In Brindley, S. (ed), Teaching English, 31-42. New York: Routledge.

Krashen, S. (1982). Principles and Practice in Second Language Acquisition. New York: Pergammon Press

Littlewood, W. (1981). Communicative Language Teaching. United Kingdom: Cambridge University Press.

Li, W., \& Renandya, W. A. (2012). Effective approaches to teaching listening: Chinese EFL teachers' perspectives. The Journal of Asia TEFL, 9(4), 79-111.

Maniruzzaman, D. M. (2002). Basic English Language Skills. Dhaka: Friends Book Corner. National Education Policy 2010. Ministry of Education. Dhaka: Jubili Publications.

Nunan, D. (1998). Approaches to teaching listening in language classroom. In proceedings of the 1997 Korea TESOL Conference. Taejon, Korea: KOTESOL. 
Nunan, D. (2003). Practical English Language Teaching. The McGraw Hill Companies.

Rost, M. (2002). Teaching and researching listening. England: Longman.

Underwood, M. (1989). Teaching listening. London: Longman.

Ur, P. (1995). A Course in Language Teaching. Practice and Theory. Cambridge: Cambridge University Press.

Vandergrift, L., (2004). Listening to learn or learning to listen? Annual Review of Applied Linguistics, 24, 3-25.

Yagang, F. (1994). Listening: Problems and Solutions. In T. Kral (Ed.), Teacher Development: Making the Right Moves. Washington, DC: English Language Programs Division, USIA.

\section{Copyrights}

Copyright for this article is retained by the author(s), with first publication rights granted to the journal. This is an open-access article distributed under the terms and conditions of the Creative Commons Attribution license (https://creativecommons.org/licenses/by/4.0) 